\title{
Effects of pre-overwintering conditions on eupyrene and apyrene spermatogenesis after overwintering in Polygonia c-aureum (Lepidoptera: Nymphalidae)
}

\section{Authors: Satoshi Hiroyoshi, Jin Yoshimura, Kikuo Iwabuchi, Gadi V. P. Reddy, and Jun Mitsuhashi}

NOTICE: this is the author's version of a work that was accepted for publication in Journal of Insect Physiology. Changes resulting from the publishing process, such as peer review, editing, corrections, structural formatting, and other quality control mechanisms may not be reflected in this document. Changes may have been made to this work since it was submitted for publication. A definitive version was subsequently published in Journal of Insect Physiology, [VOL\# 100, July 2017] DOI\# 10.1016/j.jinsphys.2017.04.008

Hiroyoshi, Satoshi, Jin Yoshimura, Kikuo Iwabuchi, Gadi V. P. Reddy, and Jun Mitsuhashi. "Effects of pre-overwintering conditions on eupyrene and apyrene spermatogenesis after overwintering in Polygonia c-aureum (Lepidoptera: Nymphalidae)." Journal of Insect Physiology 100 (July 2017): 1-8. DOI: 10.1016/j.jinsphys.2017.04.008.

Made available through Montana State University's ScholarWorks scholarworks.montana.edu 


\title{
Effects of pre-overwintering conditions on eupyrene and apyrene spermatogenesis after overwintering in Polygonia c-aureum (Lepidoptera: Nymphalidae)
}

\author{
Satoshi Hiroyoshi ${ }^{\mathrm{a}, *}$, Jin Yoshimura ${ }^{\mathrm{b}, \mathrm{c}, \mathrm{d}}$, Kikuo Iwabuchi ${ }^{\mathrm{a}}$, Gadi V.P. Reddy ${ }^{\mathrm{e}}$, Jun Mitsuhashi ${ }^{\mathrm{a}, 1}$ \\ a Laboratory of Applied Entomology, Faculty of Agriculture, Tokyo University of Agriculture and Technology, Fuchu, Tokyo 183-8509, Japan \\ b Graduate School of Science and Technology and Department of Mathematical and Systems Engineering, Shizuoka University, Hamamatsu 432-8561, Japan \\ c Marine Biosystems Research Center, Chiba University, Kamogawa, Chiba 299-5502, Japan \\ d Department of Environmental and Forest Biology, State University of New York College of Environmental Science and Forestry, Syracuse, NY 13210, USA \\ e Montana State University, Western Triangle Ag Research Center, 9546 Old Shelby Rd., P. O. Box 656, Conrad, MT 59425, USA
}

\begin{abstract}
A B S T R A C T
Sperm polymorphism is widely known in invertebrates. In insects, Lepidoptera has two types of sperm: nucleated eupyrene (fertile) sperm and anucleated apyrene (unfertile) sperm. These sperm types are produced during postembryogenesis, and eupyrene spermatogenesis precedes apyrene spermatogenesis. During overwintering, spermatogenesis stops and a portion of undifferentiated-stage spermatocytes degenerate. After overwintering, spermatogenesis restarts with unaffected spermatogonia. However, how new spermatozoa arise in the adult testes after overwintering is not known in Lepidoptera. In this study, we investigated the spermatogenesis events in the nymphalid butterfly Polygonia c-aureum after overwintering under various environmental conditions. Our results indicate that both eupyrene and apyrene spermatogenesis restart at any stopping stage and sperm of these types are regenerated in no particular order after adult insect overwintering. This suggests that the spermatogenesis occurring after overwintering proceeds without embryogenetic restrictions related to the developmental sequence.
\end{abstract}

\section{Introduction}

In insects, sperm polymorphism is known in Lepidoptera, Coleoptera, Orthoptera, Dictyoptera, Hemiptera, Hymenoptera, and Diptera (Schrader, 1960; Tibout, 1980; Joly et al., 1989; Besac et al., 1991; Lachaise and Joly, 1991; Bircher et al., 1995; Dallai, 2014; Dallai et al., 2016), but most of these forms are variations of eupyrene sperm. For example, the heteropteran bug Raphingaster nebulosi has two types of sperm, which differ in length and the size of the flagella (Mercati and Dallai, 2016). One conspicuous instance of sperm polymorphism is apyrene (anucleate) sperm, which are not involved in fertilization (Katsuno, 1977). Apyrene sperm have been found in many lepidopteran species, except for the primitive moths (Sonnenschein and Hauser, 1990; Hamon and Chauvin, 1992), and are also known in the smaller European elm bark beetle, Scolytus multistriatus (Coleoptera: Curculionidae) (Jumper and Cannon, 1975).

Spermatogenesis is initiated in the germarium, which consists of densely packed undifferentiated germ cells ( $=$ spermatogonia). Each spermatogonium becomes covered with a mantle of somatic cells and divides repeatedly to form a spermatocyst (cyst) containing many spermatocytes derived from a single spermatogonium. In each cyst, spermatocytes continue division to form spermatids, and eventually convert into sperm. A spermatocyte destined to become apyrene sperm has, at first, a nucleus. The chromosomes form masses at the meiotic metaphases, are irregularly distributed at anaphase, and then spermatids have numerous micronuclei, which are eventually discarded from the cyst (Friedländer and Wahrman, 1971; Friedländer and Miesel, 1977; Leviatan and Friedländer, 1979). Further, in the apyrene spermatid only the flagellum elongates, while the nucleus remains spherical and appears at variable sites along the flagellum (Friedländer and Benz, 1981). One of the most obvious differences between eupyrene and apyrene sperm, except for the presence or absence of a nucleus, is the presence or absence of a glycocalyx (lacinate appendages) (Dallai et al., 2016). 


\begin{tabular}{|l|ccc|}
\hline $\begin{array}{l}\text { Rearing } \\
\text { conditions }\end{array}$ & pre-overwintering & overwintering & post-overwintering \\
& $\mathbf{3 0 \mathrm { d } \text { SD }}$ & $60 \mathrm{~d}$ & $30 \mathrm{~d} \mathrm{LD}$ \\
\hline
\end{tabular}

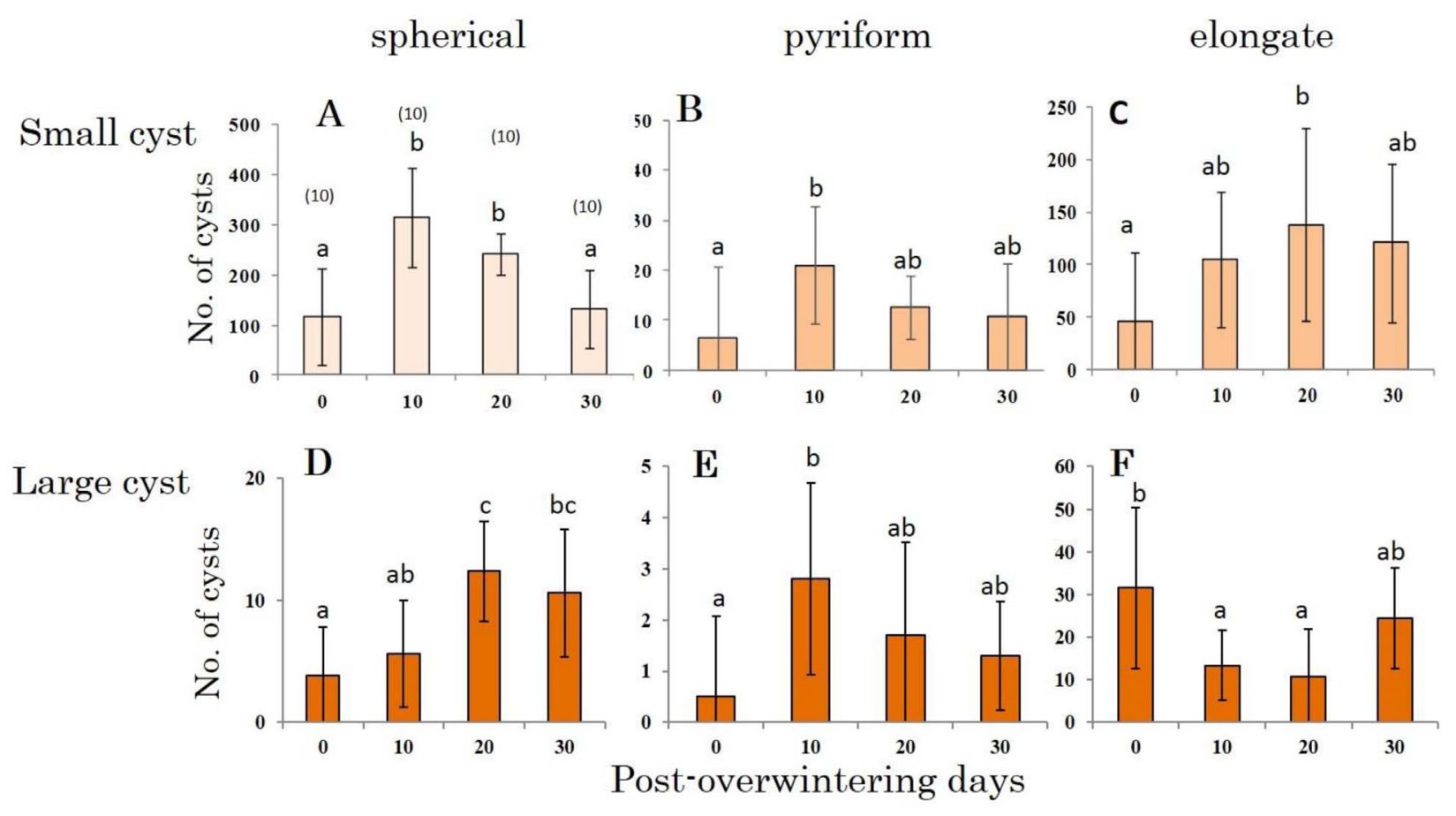

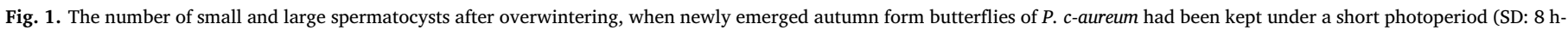

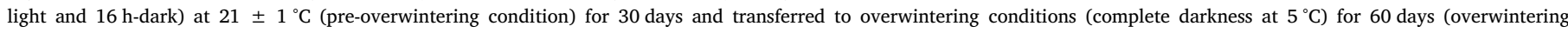

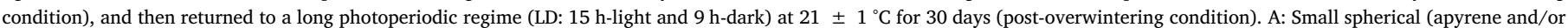

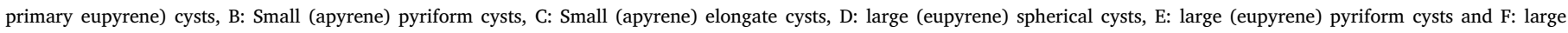

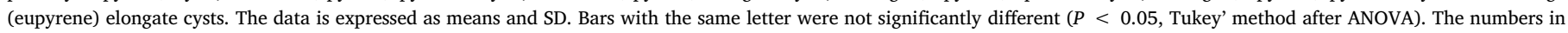
parenthesis indicate the sample size.

The differentiation of eupyrene and apyrene sperm clarified by Friedländer's studies on Lepidoptera can be summarized as follows: 1) cysts at the primary spermatocyte stage destined for apyrene and eupyrene sperm have the potential to become either; 2) the first and key event of dichotomy into eupyrene and apyrene sperms is the failure of the homologous chromosomes of the presumptive apyrene cells to pair properly during the zygotene stage of meiosis; 3) eupyrene spermiogenesis (the final spermatozoa formation process of spermatogenesis) precedes apyrene spermiogenesis; 4) late-formed primary spermatocytes develop into apyrene sperm by the action of an apyrene spermatogenesis-inducing factor (ASIF) (Friedländer and Wahrman, 1971; Friedländer, 1976, 1991; Friedländer and Miesel, 1977; Leviatan and Friedländer, 1979; Friedländer and Benz, 1982; Friedländer et al., 2005). Thus, early developed cysts become eupyrene sperms, whereas late developed cysts become apyrene sperms by an ASIF.

However, the spermatogenic stage at which sperm differentiation occurs remains disputed. According to some authors, eupyrene and apyrene sperms are cytologically identical until the primary spermatocyte stage. In contrast, both Katsuno (1987) and Hiroyoshi (1999) found the differentiation of these sperm types to occur between the spermatogonium stage and the prophase of the primary spermatocyte stage.

Both eupyrene and apyrene spermatogenesis are strongly linked with the developmental stages of insects. Eupyrene meiotic metaphases are seen in the testes of the penultimate and the final instar larvae or pupae, and then decrease considerably or mostly disappear at a speciescharacteristic stage of pupal development. In contrast, the earliest apyrene metaphase is first seen close to the time of pupation or after pupation, and continue to exist side by side with a few eupyrene spermatocytes for the remainder of the insect's life (Lai-Fook, 1982a; Tschudi-Rein and Benz, 1990; Hiroyoshi, 1999). These results cannot be explained by the ASIF hypothesis, which denies the possibility that eupyrene and apyrene spermatogenesis co-occur.

Overwintering causes the apparent stoppage of spermatogenesis, and existing spermatocytes degenerate. After overwintering, new spermatozoa are produced by differentiation from spermatogonia (Friedländer and Benz, 1982; Cloutier and Beck, 1963; Numata and Hidaka, 1980; Shimoda et al., 2007). The spermatogenic stage at which the spermatogenic cells interrupt their development by overwintering is correlated with the developmental stage (larva or pupa) at which the species overwinters (Friedländer et al., 2005). In adult diapause of the desert beetle Omorgus freyi, (Trogidae) spermatozoa and late spermatids are completely lysed, and after overwintering new eupyrene spermatozoa are produced (Friedländer and Scholtz, 1993). However, how new eupyrene and apyrene spermatozoa are supplied in adult testes after termination of adult diapause is unknown.

The nymphalid butterfly Polygonia c-aureum undergoes adult diapause in association with a seasonal diphenism, i.e., summer- and autumn-forms; autumn-form butterflies enter diapause after adult emergence and overwinter, and then start reproduction after overwintering. Both diapause induction and seasonal diphenism are triggered by a short photoperiod and lower temperature during the larval stage (Hidaka and Aida, 1963). Our previous study on the spermatogenesis of $P$. c-aureum found that sperm differentiation occurs before the spermatocyte stage and that eupyrene spermiogenesis occurs at the 


\begin{tabular}{|l|c|c|c|}
\hline $\begin{array}{l}\text { Rearing } \\
\text { conditions }\end{array}$ & pre-overwintering & overwintering & post-overwintering \\
& $30 \mathrm{~d}$ SD & $60 \mathrm{~d}$ & $30 \mathrm{~d}$ SD \\
\hline
\end{tabular}

spherical pyriform elongate
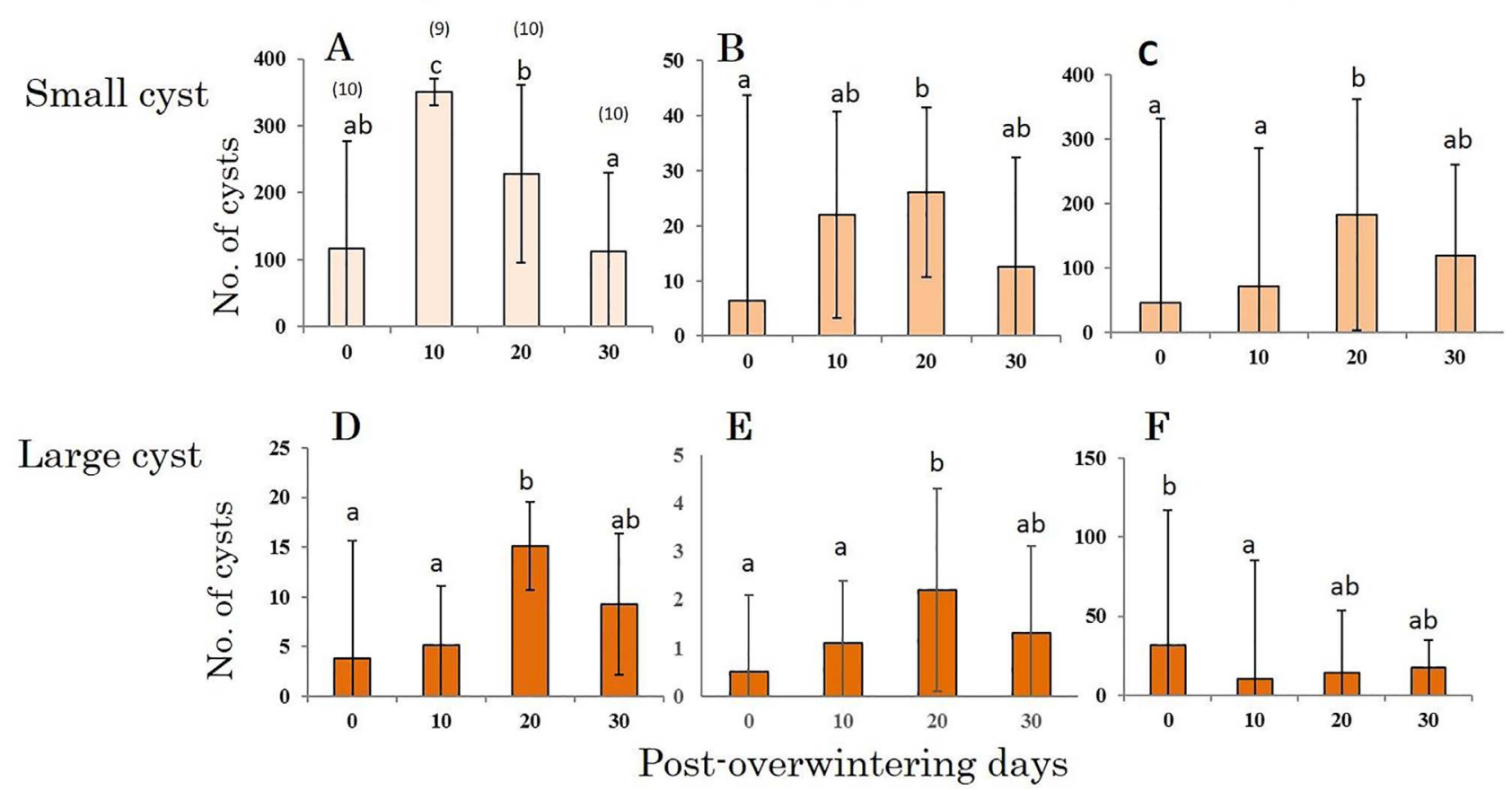

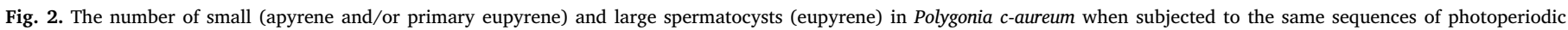

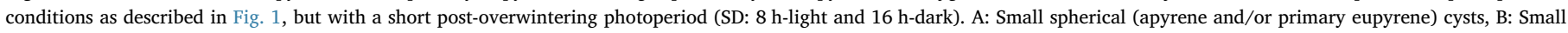

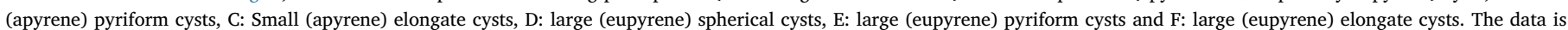

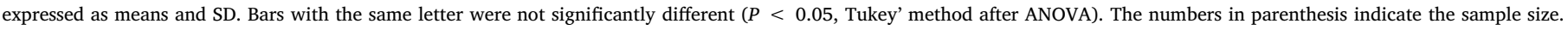

sleeping stage of the 4th (penultimate) larval instar and that apyrene spermiogenesis then starts as the butterfly approaches pupation (Hiroyoshi, 1999). Like other lepidopteran species (Tschudi-Rein and Benz, 1990), eupyrene spermatogenesis of $P$. c-aureum precedes apyrene spermatogenesis. Photoperiods, seasonal forms, and imaginal diapause have no effect on adult spermatogenesis. Although eupyrene spermatogenesis declines in the adult stage, it continues throughout adulthood. As testis size increased after overwintering (Hiroyoshi, 2000), we assume that spermatogenesis may also recover. Here we show by quantitative analysis in the nymphalid butterfly $P$. c-aureum that after overwintering, both eupyrene and apyrene spermatogenesis restart at any stopping stage and proceed simultaneously.

\section{Materials and methods}

\subsection{Insect source and rearing}

Polygonia c-aureum larvae were collected in the field in Tokyo and Saitama Prefectures in Japan and reared in the laboratory at $21 \pm 1{ }^{\circ} \mathrm{C}$ and a long day length (15:9 h L:D) photoperiod. Only individuals from eggs laid by summer-form adults were used for experiments, because the offspring of autumn-form females are likely to become the summerform under any photoperiodic conditions due to a maternal effect (Hidaka and Takahashi, 1967). Eggs were surface-sterilized with 3\% formaldehyde solution for $30 \mathrm{~min}$, washed in tap water, air-dried, and then placed in a plastic Petri dish $(9 \mathrm{~cm}$ dia. $\times 2 \mathrm{~cm}$ depth) until hatch. Larvae were reared in groups of 30 to 40 on pieces of filter paper in a glass Petri dish (12 cm dia. $\times 3 \mathrm{~cm}$ depth or $15 \mathrm{~cm}$ dia. $\times 4 \mathrm{~cm}$ depth) on fresh leaves of Humulus japonicas (Moraceae). Larval density in each
Petri dish was gradually reduced after reaching the 4th instar to accommodate for greater feeding per larva. The exact density was approximately 10 larvae for the 4th (penultimate) substage and approximately 5 larvae for the final substage. After pupation, pupae were transferred into polythene bags with soft tissue paper to absorb the meconium and to facilitate normal eclosion. Immature stages were reared under a short day length photoperiodic regime (8:16 h L:D)at $21 \pm 1{ }^{\circ} \mathrm{C}$. After adult emergence, females and males were kept separately in cages $(17 \times 16.5 \times 46 \mathrm{~cm})$ covered with $\operatorname{Saran}^{\circledast}$ net in groups of $30-40$ individuals. Adults were fed on $10 \%$ sugar solution absorbed in cotton. To investigate the process of spermatogenesis, 5-20 adults were prepared for each age.

\subsection{Classification of spermatocysts}

Eupyrene sperm and apyrene sperm originally differ in their size; the primary spermatocyte destined to produce eupyrene sperm is already much longer than that for apyrene sperm (Loeb and Birnbaum, 1981; Lai-Fook, 1982a,b; Bodnaryk and Gerber, 1988; Tschudi-Rein and Benz, 1990; Hiroyoshi, 1999). Gage (1994) examined the sperm size of 70 butterfly species and found eupyrene sperm to be much longer (up to 5-fold) than apyrene sperm in all of them. By the mid-prophase of meiosis, eupyrene and apyrene spermatocytes become easily distinguishable (Hiroyoshi, 1999). In this study, to quantitatively examine the state of embryogenesis, instead of checking whether the nucleus was present or lacking in each spermatocyte, spermatid and sperm, we distinguished as eupyrene or apyrene types according to their size under a phase-contrast microscope: eupyrene spermatocyst in the spermatocyte, spermatid, and sperm stages was approximately 


\begin{tabular}{|lrcc|}
\hline $\begin{array}{l}\text { Rearing } \\
\text { conditions }\end{array}$ & pre-overwintering & overwintering & post-overwintering \\
\hline
\end{tabular}

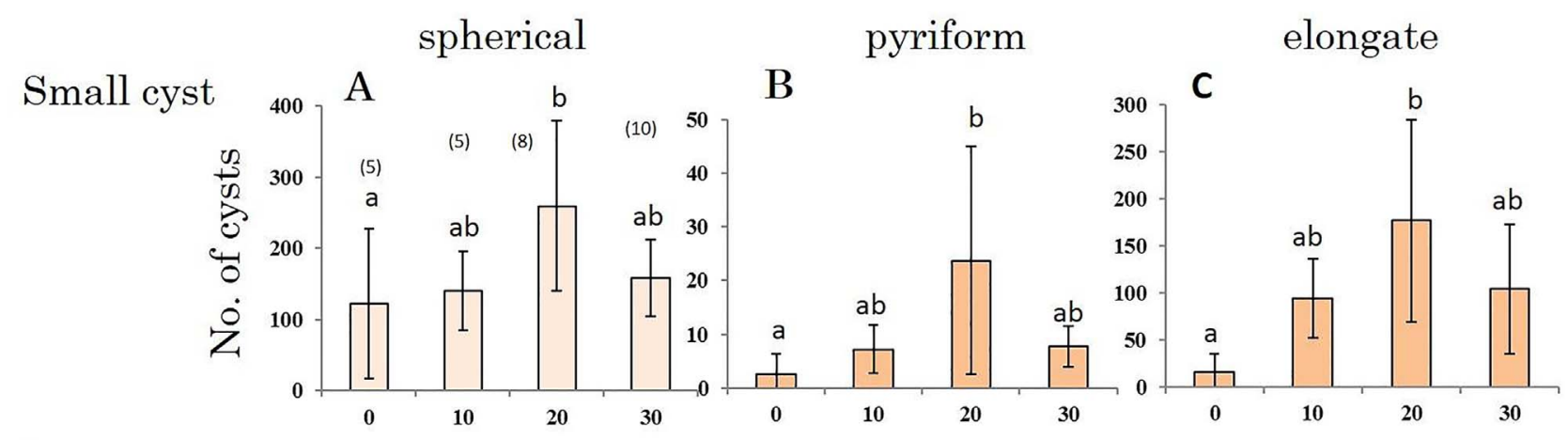

Large cyst

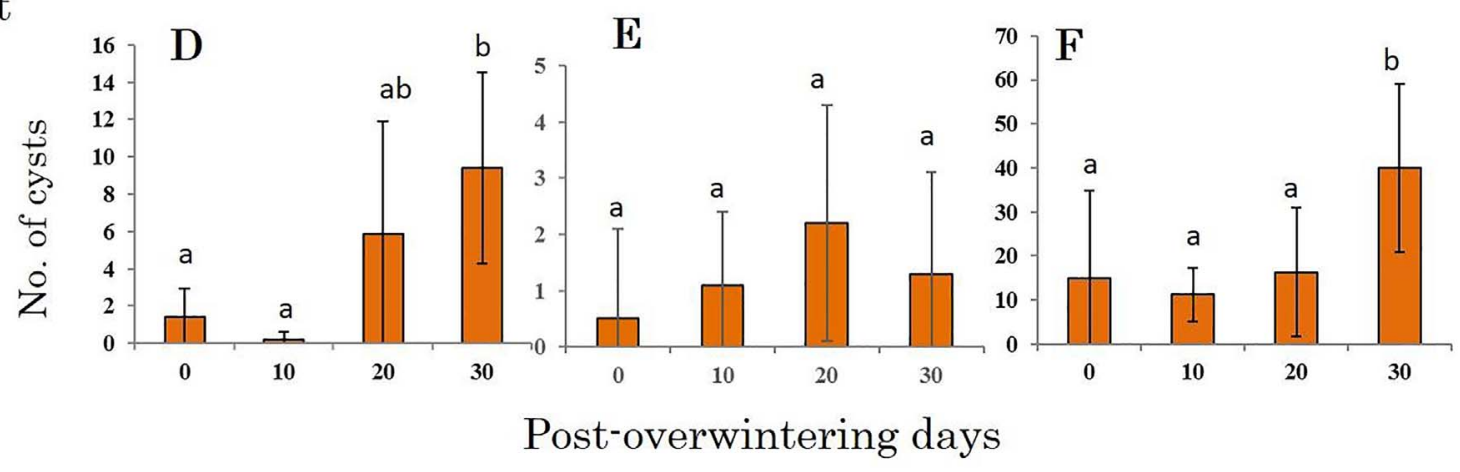

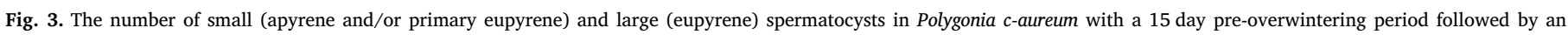

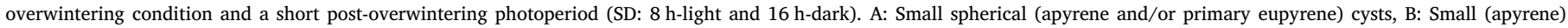

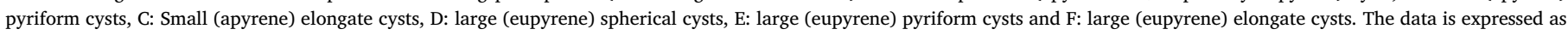
means and SD. Bars with the same letter were not significantly different $(P<0.05$, Tukey' method after ANOVA). The numbers in parenthesis indicate the sample size.

twofold longer and thicker than apyrene spermatocyst in the same stage. Cysts were categorized according to their size and morphology as follows: (1) small spherical cysts (undifferentiated spermatogonia or apyrene spermatocytes), (2) small pyriform cysts (spermatids destined for apyrene sperm), (3) small elongate cysts (apyrene sperm), (4) large spherical cysts more than $80 \mu \mathrm{m}$ (spermatocytes destined for eupyrene sperm), (5) large pyriform cysts (spermatids destined for euyrene sperm), and (6) large elongate cysts (eupyrene sperm).

\subsection{Experimental procedures}

Preliminary examinations revealed that adult diapause of $P . c$ aureum is maintained under short photoperiods and low temperature for a certain period, and broken under long photoperiods, high temperature, and by aging. As autumn-form butterflies emerge from the last half of September to October in the field, the time to overwinter differs with the date of adult emergence for each individual. Thus, we assessed the effects of pre-overwintering period on spermatogenesis in this butterfly. The single testis (formed by the fusion of the original two testes at the prepupal stage) (Hiroyoshi, 2016) was dissected out in saline solution ( $8.6 \mathrm{~g} \mathrm{NaCl}, 0.33 \mathrm{~g} \mathrm{CaCl}_{2}$, and $0.1 \mathrm{~g} \mathrm{KCl}$ per liter distilled water) and ruptured with forceps to release spermatocysts. The cysts were categorized into six classes, as mentioned above, and were counted except for small spherical cysts less than $40 \mu \mathrm{m}$. Experiments were designed as follows. First, newly emerged autumn-form butterflies were kept under a short-day length (SD; $8 \mathrm{~h}$ light: $16 \mathrm{~h}$ dark) photoperiod at $21 \pm 1{ }^{\circ} \mathrm{C}$ (pre-overwintering conditions) for 30 days and transferred to overwintering conditions (continuous darkness at $5{ }^{\circ} \mathrm{C}$ ) for 60 days, and then returned to LD or SD photoperiodic conditions at
$21 \pm 1{ }^{\circ} \mathrm{C}$ for further 30 days (post-overwintering conditions). Adults at pre-overwintering and post-overwintering stages were fed $10 \%$ sugar solution, while those in overwintering conditions were not fed any food or water. In the second experiment, autumn-form butterflies, were held after emergence under SD conditions at $21 \pm 1{ }^{\circ} \mathrm{C}$ for 15 days, transferred to the overwintering conditions for 60 days, and then removed to post-overwintering conditions ( $\mathrm{LD}$ at $21 \pm 1{ }^{\circ} \mathrm{C}$ ) for 30 days. In the third experiment, autumn-form butterflies, were held after emergence under SD conditions and $21 \pm 1{ }^{\circ} \mathrm{C}$ for 45 days, transferred to overwintering conditions for 60 days, and then removed to post-overwintering conditions ( $\mathrm{LD}$ at $21 \pm 1{ }^{\circ} \mathrm{C}$ ) for 30 days.

The data on the number of each type of cyst at each age after overwintering conditions was subjected to analysis of variance (ANOVA), and mean separations were done with a Tukey's method. As the data was not normal distributed due to the small sample size, the number of each type of cyst between before and after overwintering conditions was analyzed by Mann-Whitney $U$ test. A significance level of $\mathrm{P}<0.05$ was used for all analyses.

\section{Results}

\subsection{Spermatogenesis of male adults at 30 days pre-overwintering, overwintering, and post-overwintering}

In $P$. c-aureum adults held at pre-overwintering conditions (short photoperiod and $21 \pm 1{ }^{\circ} \mathrm{C}$ ) for 30 days, then an overwintering condition (continuous darkness at $5{ }^{\circ} \mathrm{C}$ ) for two months and then one of two post-overwintering conditions (long or short photoperiod) at $21 \pm 1{ }^{\circ} \mathrm{C}$ for 30 days, we observed the state of spermatogenesis of 


\begin{tabular}{|l|ccc|}
\hline \multirow{2}{*}{$\begin{array}{l}\text { Rearing } \\
\text { conditions }\end{array}$} & pre-overwintering & overwintering & post-overwintering \\
\cline { 2 - 4 } & $\mathbf{4 5}$ d SD & $60 \mathrm{~d}$ & $30 \mathrm{~d}$ LD \\
\hline
\end{tabular}

spherical pyriform elongate

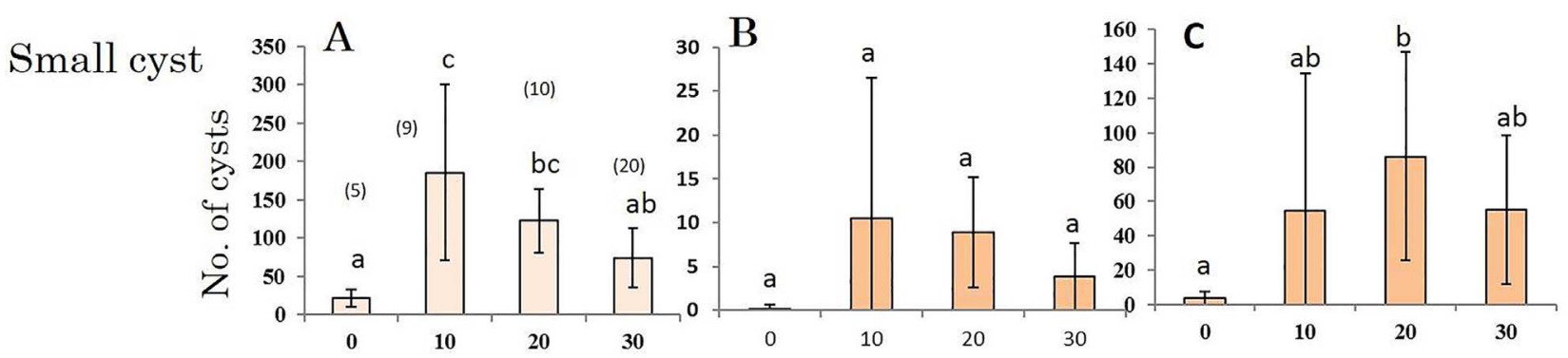

Large cyst

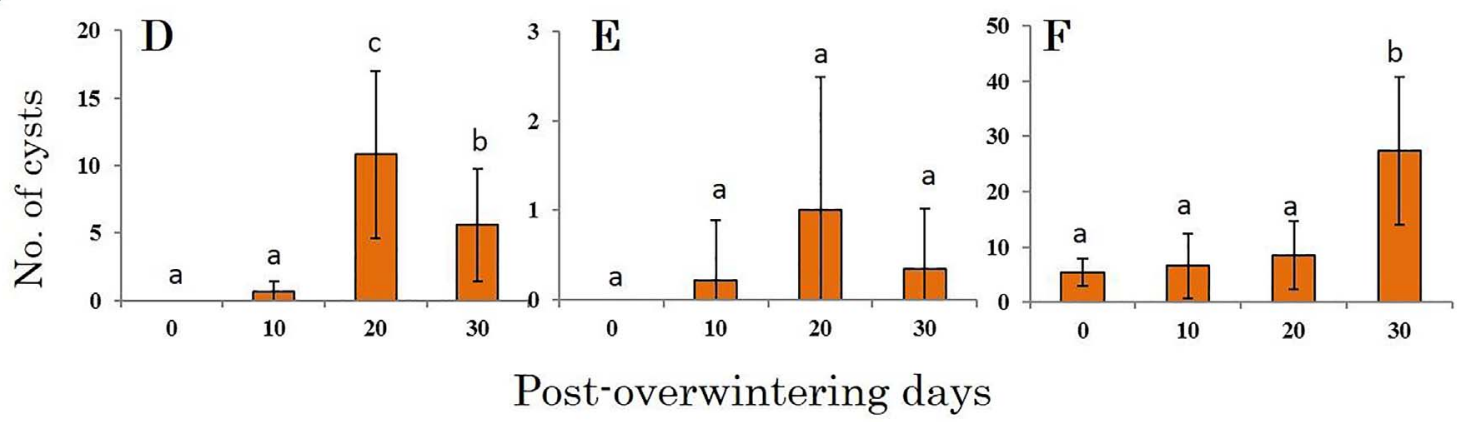

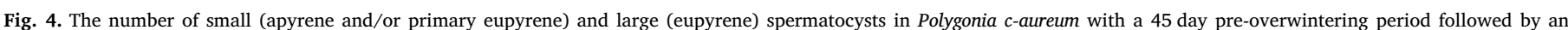

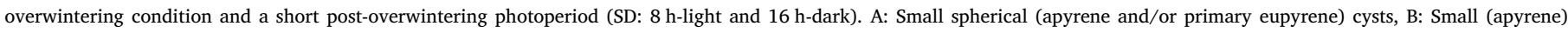

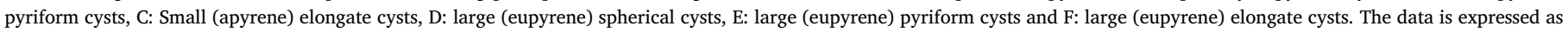
means and SD. Bars with the same letter were not significantly different $(P<0.05$, Tukey' method after ANOVA). The numbers in parenthesis indicate the sample size.

\section{Eupyrene spermatogenesis precedence}

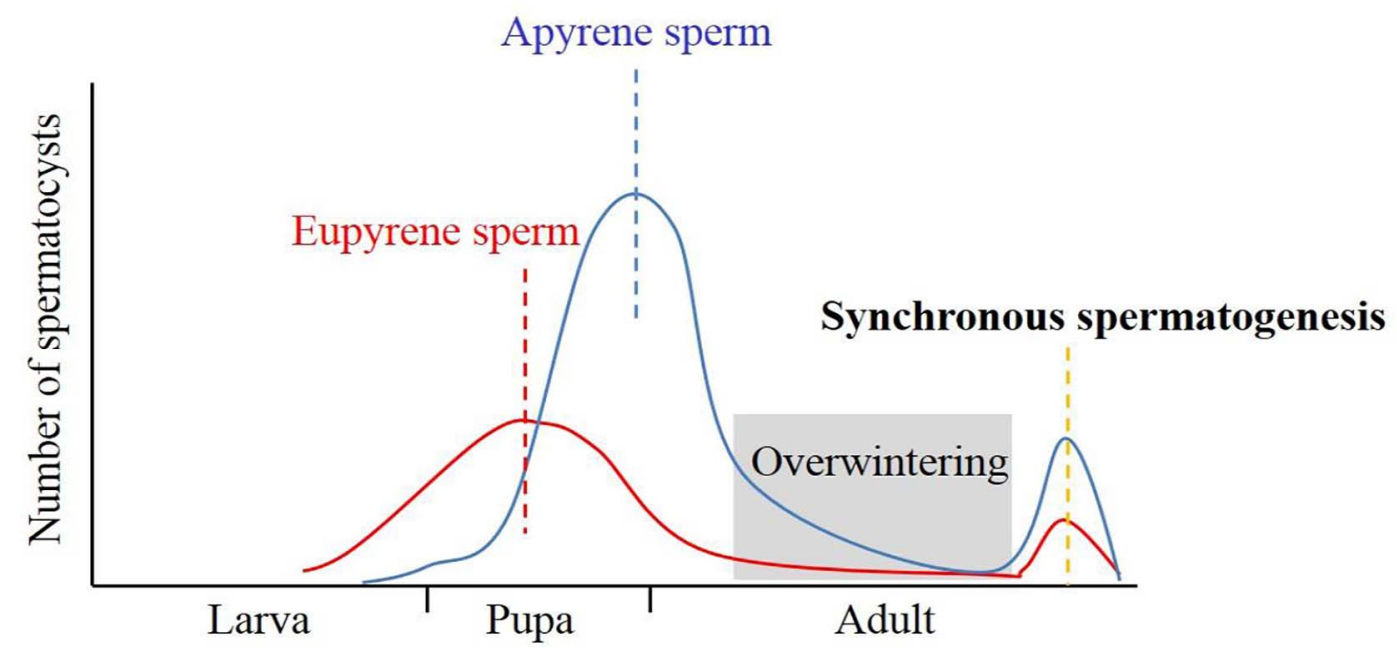

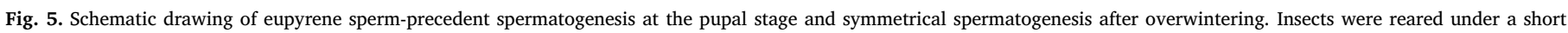

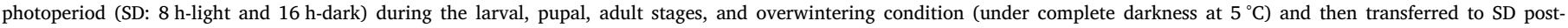
overwintering conditions.

both eupyrene and apyrene sperms, and also examined the effect of the length of pre-overwintering phase $(15,30$ and 45 days) on the state of spermatogenesis after overwintering.

As spermatogenesis advances, the cyst shape shifts from spherical to pyriform and then begins to elongate. Large spherical cysts first appeared during the penultimate larval instar, while small spherical cysts destined for apyrene sperm first appear during the last (5th) larval instar. Our previous study showed that the number of both large and small spherical cysts increases with larval growth, peaks at approximately 200 during the last instar and 1000 during the late pupal stage, 
respectively, and then begins to decrease. Newly emerged male adults have approximately 800 small and 30 large spherical cysts, and approximately 800 small and 400 large elongated cysts (Hiroyoshi, 1999).

In $P$. c-aureum adults kept at pre-overwintering conditions for 30 days and then overwintering (diapause) conditions for 60 days, the number of small spherical cysts (cysts destined for apyrene sperm or undifferentiated cysts) decreased to approximately 100 and large spherical cysts to less than five (Fig. 1A,D). However, when the adults were transferred to the post-overwintering conditions, small spherical cysts significantly increased from day 0 to day $10 \quad(\mathrm{n}=10$, zvalue $=5.433, P<0.001$, by Tukey's method after ANOVA), suggesting that apyrene spermatogenesis and/or primary spermatogenesis to produce eupyrene sperm were re-activated after overwintering (Fig. 1,A). An increase in small (apyrene) pyriform and elongated cysts came after the increase in small spherical cysts (Fig. 1B,C). The number of large (eupyrene) spherical cysts also increased from day 10 to day 20 after overwintering (diapause) $(\mathrm{n}=10, \mathrm{z}=-3.548, P<0.01$, by Tukey's method after ANOVA) (Fig. 1D). These results suggest that both eupyrene and apyrene spermatogenesis from the spermatogonium simultaneously occurred after overwintering. Furthermore, small elongated (apyrene) cysts increased as early as day 20, suggesting that the cysts may have developed also from the spherical or pyriform cysts resting after overwintering (Fig. 1A-C).

Similar results were obtained when $P$. c-aureum adults were held under short photoperiod post-overwintering conditions after diapause (Fig. 2). These results imply that after overwintering, the spermatogenesis of both eupyrene and apyrene sperm restarts at any stopping stage, and that photoperiod length (short or long) after overwintering had no impact on the resumption of spermatogenesis.

\subsection{Spermatogenesis of males under held for 15 or 45 days under pre- overwintering, overwintering, and post-overwintering conditions}

To determine what effect the length of the pre-overwintering period might have on spermatogenesis, $P$. c-aureum adults were kept under pre-overwintering conditions for 15 or 45 days, and the results compared with that for 30 days above. As spermatogenesis decreased with adult age, males exposed for 15 days had more cysts of each type than those exposed for 45 days. When the pre-overwintering period was 15 days, the number of large (eupyrene) spherical cysts, pyriform cysts and elongate cysts at the end of overwintering were 1.4, 0.4 and 5.4, respectively (Fig. 3D,E,F). In contrast, when the pre-overwintering period was lengthened to 45 days, large (eupyrene) spherical cysts and pyriform cysts disappeared completely during overwintering (Fig. 4D,E), and the number of eupyrene elongate cysts decreased to 5.4 after overwintering (Fig. 4F). No significant differences were observed in any types of large (eupyrene) cysts after overwintering between pre-overwintering periods of 15 (Fig. 3D,E,F) and 30 days (Fig. 1D,E,F) $(P>0.05$, Mann-Whitney $U$ test). A similar pattern was also observed in small (apyrene) sperm (Fig. 1B,C, and Fig. 3B,C). In both eupyrene and apyrene sperm, even if once most spherical cysts disappeared during overwintering, spermatogenesis restarted afterwards in all of the spermatogenetic stages, even from the regeneration of small spherical cysts (Figs. 1-4).

\section{Discussion}

\subsection{Simultaneous spermatogenesis of eupyrene and apyrene sperm after overwintering}

Our study showed that, after degeneration of spermatocysts during overwintering (though some undifferentiated cysts survived), both eupyrene and apyrene spermatogenesis of $P$. c-aureum restarted to supply the loss of cysts after overwintering irrespective of pre- or postoverwintering conditions (Fig. 5). This is the first report to demonstrate the simultaneous occurrence of eupyrene and apyrene spermatogenesis after overwintering. We found both eupyrene and apyrene spermatogenesis to be able to restart following any stopping stage, and cysts lost during overwintering were replenished in no particular order (e.g., without eupyrene spermatogenesis precedence). In the case of Coleopteran insects, spermatogenesis and subsequent sperm storage are usually active in the adult stage, as they are for example in the sweet potato weevil Cylas formicarius (Hiroyoshi et al., 2016). Thus, spermatogenesis and sperm storage are suppressed during adult diapause or overwintering and resume after that, as in the boll weevil Anthonomus grandis (Brazzel and Newsom, 1959; Spurgeon and Raulston, 1998), the apple blossom weevil Anthonomus pomorum (Čtvrtečka and Ždárek, 1992) and the West Indian sweetpotato weevil Euscepes postfasciatus (Hiroyoshi and Moriya, 2001). In various leaf beetles (Ashida and Matsuda, 1983) including the Japanese green duck leaf beetle Gastrophysa atrocyanea (Ashida, 1981), spermatogenesis is active during or after adult diapause. On the other hand, spermatogenesis is usually inactive in the adult stage in Lepidoptera and testis volume (or size) is closely related to the degree of spermatogenesis (Hiroyoshi, 1999, 2000). Decreased spermatogenesis or testis shrinkage are seen in many lepidopterans, including the Brazilian skipper Calpodes ethlius (LaiFook, 1982b), the giant looper Boarmia selenaria (Scheepens and Wysoki, 1985), the tobacco budworm Heliothis virescens (Loeb and Birnbaum, 1981), the cabbage butterfly Pieris brassicae (Junnikkala, 1985), the coconut black-headed caterpillar Opisina arenosella (TschudiRein and Benz, 1990) and the sweet potato hornworm Agrius convolvuli (Shimoda et al., 2007). Thus, the recovery of spermatogenesis after overwintering in $P$. c-aureum is surprising.

During the post-embryonic development of $P$. c-aureum, eupyrene and apyrene spermatogenesis peaked during the last larval instar and pupal stages, respectively (Fig. 5). In P. c-aureum, as in other lepidopteran insects, eupyrene spermatogenesis precedes apyrene spermatogenesis (Hiroyoshi, 1999). After that, these cysts shift their shape into pyriform and then elongate form, and at adult emergence a sufficient number of sperm are contained in the testis (Hiroyoshi, 1999). This study revealed that overwintering conditions strongly reduced the number of spermatocysts of varying stages, probably due to low temperature and no food supply, and that, in such cases, both eupyrene and apyrene sperms were complemented by the production of sperm from spermatocysts resting at various spermatogenic stages, even from the regeneration of small spherical cysts.

\subsection{Sperm migration from the testis to the duplex}

Elongated cysts eventually form bundles in Lepidoptera. Eupyrene sperm migrate as bundles within the male reproductive organs, whereas apyrene sperm bundles dissociate into single sperm, when they migrate from the testis to the vas eferens (Riemann, 1970; Riemann et al., 1974; Katsuno, 1977). Mature sperm are transferred from the testis to the duplex via the vasa deferens and stored there until mating (Holt and North, 1970; Riemann et al., 1974; LaChance et al., 1977; LaChance, 1984). Eupyrene sperm movement is entrained by a circadian rhythm demonstrated in vitro (Giebultowicz et al., 1988, 1989; Bebas et al., 2001, 2002; Gvakharia et al., 2003). Apyrene sperm movement starts two days before adult emergence, while eupyrene sperm movement starts the day before adult emergence in P. c-aureum (Hiroyoshi, 1997). After adult emergence, the number of eupyrene sperm bundles transferred to the duplex increases with age and apyrene sperm likely increases with age in the duplex as well (Hiroyoshi and Mitsuhashi, 1998). As sperm formed in the testis migrates into the duplex, the testis shrinks with adult age (Hiroyoshi, 2000). Thus, overwintering and subsequent increasing temperatures (and probably food intake) induce the recovery of spermatogenesis of this butterfly. It seems that low temperatures may reset spermatogenesis, and the conditions after overwintering may stimulate spermatogenesis. In this study, we found that the cysts of eupyrene and apyrene sperm increased simultaneously 
after overwintering, which implies that spermatogenesis occurring after overwintering proceeds without embryogenetic restrictions related to the developmental sequence.

\subsection{Function of ASIF}

The production of eupyrene sperm directly involved in fertilization is a primary event, because it precedes apyrene spermiogenesis. This type of activity may have priority over apyrene sperm production, which itself may play a role in loosening eupyrene sperm bundles but not in fertilization itself (Osanai et al., 1987). As overwintered males approach the reproductive season, the simultaneous production of eupyrene and apyrene sperm may reflect the fact that both types of sperm are required for providing the fresh sperm in the seminal receptacle.

It is supposed that an apyrene-spermatogenesis-inducing factor (ASIF) is required to form apyrene sperm (Jans et al., 1984). Friedländer and Benz (1981) cultured testes of codling moth Laspeyresia pomonella removed from late 4th and 5th instar larvae. Cysts derived from 4th instar insects developed only eupyrene spermatids, while cysts removed on the 4th day of the 5th larval instar developed both eupyrene and apyrene spermatids. Since then, only apyrene sperm were produced in which the ASIF is already present. However, it is known that both types of sperm can be found during adulthood, contradicting the ASIF hypothesis (Lai-Fook, 1982a,b; Tschudi-Rein and Benz, 1990; Hiroyoshi, 1999). It may be that primary spermatocytes have a relatively short period when they are sensitive to the ASIF (Friedländer, 1976; Friedländer and Reynolds, 1988; Friedländer, 1991; Friedländer, 1997). However, our study found that eupyrene and apyrene spermatogenesis simultaneously advanced in overwintered $P$. c-aureum, a result which suggests that the concentration of ASIFs, if any, may decline in overwintered males. Further study is needed to clarify whether ASIFs are absent to all practical purposes or not under these conditions.

\subsection{Why spermatogenesis revives after overwintering}

Eupyrene and apyrene sperm of $P$. c-aureum become fully mature in the upper portion of the vas deferens after adult emergence (Hiroyoshi, 1999). In summer-form butterflies, most females mate within the first three days after adult emergence. In contrast, autumn form females do not mate until after several weeks under laboratory conditions and mainly reproduce only after overwintering (Endo, 1973). Thus, most autumn-form females mate with autumn-form males with sperm produced before overwintering (Hiroyoshi and Mitsuhashi, 1998) and those newly supplied after overwintering (this study).

In the field, most overwintered butterflies reproduce in spring and then disappear in May in the middle of Japan. Spermatogenesis ability after overwintering would be useful to supply fresh sperm, particularly when the butterfly lives for a long time. Populations of $P$. c-aureum in the north of Japan are univoltine (autumn-form) with long longevity. In some insects, sperm have limited longevity and thus die during early adulthood (Yamagishi et al., 1992: Radhakrishnan and Fedorka, 2011). In such species, long-term production of fresh sperm may be valuable to avoid sperm with lowered fertility. Thus, in addition to the quantitative replenishment of lost spermatocysts, supplementation of fresh sperm with high fertility may explain why spermatogenesis after overwintering has developed in P. c-aureum.

\section{Acknowledgements}

We would like to thank Dr. S. Moriya, Dr. K. Tateishi and Mr. K. Takashino for their help. Thanks are also due to Dr. T. Kuriwada for statistical analysis. Two anonymous reviewers improved the manuscript.

\section{References}

Ashida, Y., 1981. Spermatogenesis in diapausing adult of Gastrophysa atrosyanea Mot. (Coleoptera: Chrysomelidae). Jpn. J. Appl. Entomol. Zool. 25, 299-300 (in Japanese with English abstract).

Ashida, Y., Matsuda, K., 1983. Occurrence of spermatogenesis depending on voltinism in the adults of various leaf beetles (Coleoptera: Chrysomelidae). Jpn. J. Appl. Entomol. Zool. 27, 142-145 (in Japanese with English abstract).

Bebas, P., Cymborowski, B., Giebultowicz, J.M., 2001. Circadian rhythm of sperm release in males of the cotton leafworm, Spodoptera littoralis: in vivo and in vitro studies. J. Insect Physiol. 47, 859-866.

Bebas, P., Cymborowski, B., Giebultowicz, J.M., 2002. Circadian rhythm of acidification in insect vas deferens regulated by rhythmic expression of vacuolar $\mathrm{H}^{+}$-ATPase. J. Exp. Biol. 205, 37-44.

Besac, C., Joly, D., Devaux, J., Serres, C., Feneux, D., Lachaise, D., 1991. Comparative kinetics of short and long sperm in sperm dimorphic Drosophila species. Cell Motil. Cytoskeleton 19, 269-274.

Bircher, U., Jungen, H., Burch, R., Hauschteck-Jungen, E., 1995. Multiple morphs of sperm were required for the evolution of the sex ratio trait in Drosophila. J. Evol. Biol. 8, 575-588.

Bodnaryk, R.P., Gerber, G.H., 1988. Inhibition of spermiogenesis of eupyrene spermatozoa by elevated, sublethal temperatures during pupal-adult development of the bertha armyworm, Mamestra configurata Wlk. (Lepidoptera, Noctuidae). Int. J. Invertebr. Reprod. Develop. 13, 65-84.

Brazzel, J.R., Newsom, L.D., 1959. Diapause in Anthonomus grandis Boh. J. Econ. Entomol. 52, 603-611.

Cloutier, E.J., Beck, S.D., 1963. Spermatogenesis and diapause in the European corn borer, Ostrinia nubilalis. Ann. Entomol. Soc. Am. 56, 253-255.

Čtvrtečka, R., Ždárek, J., 1992. Reproductive diapause and its termination in the apple blossom weevil (Anthonomus pomorum) (Coleoptera, Curculionidae). Acta Entomologica Bohemoslovaca 89, 281-286.

Dallai, R., 2014. Overview on spermatogenesis and sperm structure of Hexapoda. Arthropod Struct. Dev. 43, 257-290

Dallai, R., Gottardo, M., Beutel, R.G., 2016. Structure and evolution of insect sperm: new interpretations in the age of phylogenomics. Annu. Rev. Entomol. 61, 1-23.

Endo, K., 1973. Hormonal regulation of mating in the butterfly, Polygonia c-aureum L. Dev. Growth Differ. 15, 1-10.

Friedländer, M., 1976. The role of transient perinuclear microtubules during spermiogenesis of the warehouse moth Ephesita cautella. J. Submicr. Cytol. 8, 319-326.

Friedländer, M., 1991. 2.2 Spermatogenesis. In: In: Vener Geest, L.P.S., Evenhuis, H.H. (Eds.), Tortricid Pests, Their Biology, Natural Enermies and Control Elsevier, Amsterdam, pp. 149-155.

Friedländer, M., 1997. Control of the eupyrene-apyrene sperm dimorphism in Lepidoptera. J. Insect Physiol. 43, 1085-1092.

Friedländer, M., Benz, G., 1981. The eupyrene-apyrene dichotomous spermatogenesis of Lepidoptera. Organ culture study on the timing of apyrene commitment in the codling moth. Int. J. Invertebr. Reprod. 3, 113-120.

Friedländer, M., Benz, G., 1982. Control of spermatogenesis resumption in postdiapausing larvae of the codling moth. J. Insect Physiol. 28, 349-355.

Friedländer, M., Miesel, S., 1977. Spermatid anucleation during the normal atypical spermatogenesis of the warehouse moth Ephestia cautella. J. Submicrosc. Cytol. 9 (2-3), 173-185.

Friedländer, M., Reynolds, S.E., 1988. Meiotic mataphases are induced by 20 hydroxyecdysone during spermatogenesis of the tobacco hornworm, Manduca sexta. J. Insect Physiol. 14, 1013-1019.

Friedländer, M., Scholtz, C.H., 1993. Two different patterns of interrupted spermatogenesis in winter diapause and summer quiescence in the desert beetle, Omorgus freyi. J. Morphol. 218, 347-358.

Friedländer, M., Wahrman, J., 1971. The number of contrioles in insect sperm: a study in two kinds of differentiating silkworm spermatids. J. Morphol. 134, 383-398.

Friedländer, M., Seth, R.K., Reynolds, S.E., 2005. Eupyrene and apyrene sperm: Dichotomous spermatogenesis in Lepidoptera. Adv. Insect Physiol. 32, 206-307.

Gage, M.J.G., 1994. Associations between body size, mating pattern, testis size and sperm lengths across butterflies. Proc. R. Soc. London B 258, 247-254.

Giebultowicz, J.M., Bell, R.A., Imberski, R.B., 1988. Circadian rhythm of sperm movement in the male reproductive tract of the gypsy moth, Lymantria dispar. J. Insect Physiol. 34, 527-532.

Giebultowicz, J.M., Riemann, J.G., Raina, A.K., Ridgway, R.L., 1989. Circadian system controlling release of sperm in the insect testes. Science 245, 1098-1100.

Gvakharia, B.O., Bebas, P., Cymborowski, B., Giebultowicz, J.M., 2003. Disruption of sperm release from insect testes by cytochalasin and $\beta$-actin mRNA mediated interference. Cell. Mol. Life Sci. 60, 1744-1751.

Hamon, C., Chauvin, G., 1992. Ultrastructural analysis of spermatozoa of Korscheltellus lupulinus L. (Lepidoptera: Hepialidae) and Micropterix calthella L. (Lepidoptera: Micropterigidae). Int. J. Insect Morphol. Embryol. 21, 149-160.

Hidaka, T., Aida, S., 1963. Day length as the main factor of seasonal form determination in Polygonia c-aureum (Lepidoptera: Nymphalidae). Zool. Sci. 4, 167-174.

Hidaka, T., Takahashi, H., 1967. Temperature conditions and maternal effects as modifying factors in photoperiodic control of the seasonal form in Polygonia c-aureum (Lepidoptera, Nymphalidae). Zool. Mag. 72, 77-83.

Hiroyoshi, S., 1997. Effects of photoperiod and age on the initiation of sperm movement in male Polygonia c-aureum (Lepidoptera: Nymphalidae). Appl. Entomol. Zool. 32, 19-25.

Hiroyoshi, S., 1999. Eupyrene and apyrene spermatogenesis in the Asian comma 
butterfly, Polygonia c-aureum (Lepidoptera: Nymphalidae). Entomol. Sci. 2, 297-305.

Hiroyoshi, S., 2000. Effects of aging, temperature and photoperiod on testis development of Polygonia c-aureum (Lepidoptera: Nymphalidae). Entomol. Sci. 3, 227-236.

Hiroyoshi, S., 2016. Effects of photoperiod on the testis fusion in the Asian comma butterfly, Polygonia c-aureum LinNaEus (Lepidoptera: Nymphalidae). Entomon 41, 159-168.

Hiroyoshi, S., Mitsuhashi, J., 1998. Effects of environmental conditions and aging on eupyrene sperm movement in male adults of Polygonia c-aureum (Lepidoptera: Nymphalidae). Zool. Sci. 25, 561-565.

Hiroyoshi, S., Moriya, S., 2001. Effects of adult temperature on male mating success in the West Indian sweetpotato weevil, Euscepes postfasciatus (Coleoptera: Curculionidae). Entomol. Sci. 4, 265-269.

Hiroyoshi, S., Kohama, T., Reddy, G.V.P., 2016. Age-related sperm production, transfer, and storage in the sweet potato weevil, Cylas formicarius (Fabricius) (Coleoptera: Curculionidae). Insect Behav. 29, 689-707.

Holt, G.G., North, D.T., 1970. Effects of gamma irradiation on the mechanism of sperm transfer in Trichoplusia ni. J. Insect Physiol. 16, 2211-2222.

Jans, P., Benz, G., Friedländer, M., 1984. Apyrene-spermatogenesis-inducing factor is present in the haemolymph of male and female pupae of the codling moth. J. Insect Physiol. 30, 495-497.

Joly, D., Cariou, M.-L., Lachaise, D., David, J.R., 1989. Variation of sperm length and heteromorhism in drosophild species. Genet. Select. Evol. 21, 283-293.

Jumper, G.S.A., Cannon Jr., W.N., 1975. Spermatogenesis in the smaller European elm bark beetle, Scolytus multisriatus. Ann. Entomol. Soc. Am. 68, 733-740.

Junnikkala, E., 1985. Testis development in Pieris brassicae parasitized by Apanteles glomeratus. Entomol. Exp. Appl. 37, 283-288.

Katsuno, S., 1977. Studies on eupyrene and apyrene spermatozoa in the silkworm Bombyx mori (Lepidoptera: Bombycidae). I. The intratesticular behavior of the spermatozoa at various stages from the 5th instar to the adult. Appl. Entomol. Zool. 12, 142-153.

Katsuno, S., 1987. Time of differentiation and determination of eupyrene and apyrene spermatozoa and resulting spermatogenesis in the silkworm, Bombyx mori L. (Lepidoptera: Bombycidae). Appl. Entomol. Zool. 22, 13-18.

Lachaise, D., Joly, D., 1991. Sperm and evolution in Drosophila: morphological and molecular aspects. NATO ASI Series H57, 201-216.

LaChance, L.E., 1984. Hybrid sterility: eupyrene sperm production and abnormalities in the backcross generations of insterspecific hybrids between Heliothis subflexa and $H$. virrescens (Lepidoptera: Noctuidae). Ann. Entomol. Soc. Am. 77, 93-101.

LaChance, L.E., Richard, R.D., Ruud, R.L., 1977. Movement of eupyrene sperm bundles from the testis and storage in the ductus ejaculatoris duplex of the male pink bollworm: effects of age, strain, irradiation, and light. Ann. Entomol. Soc. Am. 70, $647-651$.

Lai-Fook, J., 1982a. Structural comparison between eupyrene and apyrene spermiogenesis in Calpodes ethlius (Hesperidae, Lepidoptera). Can. J. Zool. 60, $1216-1230$.

Lai-Fook, J., 1982b. Testicular development and spermatogenesis in Calpodes ethlius Stoll (Hesperiidae, Lepidoptera). Can. J. Zool. 60, 1161-1171.

Leviatan, R., Friedländer, M., 1979. The eupyrne-apyrene dichotomous spermatogenesis of Lepidoptera. The relationship with postembryonic development and the role of the decline in juvenile hormone titer toward pupation. Dev. Biol. 68, 515-524.

Loeb, M.J., Birnbaum, M.J., 1981. The relationship of hemolymph osmotic pressure to spermatogenesis in the tobacco budworm, Heliothis verescens. Int. J. Invertebr. Reprod. 4, 67-79.

Mercati, D., Dallai, R., 2016. A peculiar new virus-spermatozoon association in the bug Raphigaster nebulosa (Poda) (Heteroptera-Insecta). Arthoropod Struct. Develop. 45, 64-68.

Numata, H., Hidaka, T., 1980. Development of male sex cells in the swallowtail, Papilioxuthus L. (Lepidoptera: Papilionidae) in relation to pupal diapause. Appl. Entomol. Zool. 15, 151-158.

Osanai, M., Kasuga, H., Aigaki, T., 1987. Physiological role of apyrene spermatozoa of Bombyx mori. Experientia 43, 593-596.

Radhakrishnan, P., Fedorka, K.M., 2011. Influence of female age, sperm senescence and multiple mating on sperm viability in female Drosophila melanogaster. J. Insect Physiol. 57, 778-783.

Riemann, J.G., 1970. Metamorphosis of sperm of the cabbage looper, Tricoplusia ni, during passage from the testes to the spermathecal. In: In: Baccetti, B. (Ed.), Comparative Spermatology 137. Academia Nazionale dei Lincel, Quanderono N, pp. 321-331.

Riemann, J.G., Thorson, B.J., Ruud, R.L., 1974. Daily cycle of release of sperm from the testes of the Mediterranean flour moth. J. Insect Physiol. 20, 195-207.

Scheepens, M.H.M., Wysoki, M., 1985. Testicular development, spermatogenesis and chromosomes of Boarmia selenaria Schiff. (Lepidoptera: Geometridae). Int. J. Invertebr. Reprod. Dev. 8, 337-348.

Schrader, F., 1960. Cytological and evolutionary implications of aberrant chromosome behavior in the harlequin lobe of some Pentatomidae (Heteroptera). Chromosoma (Berl.) 11, 103-128.

Shimoda, M., Kubo-Irie, M., Ohta, K., Irie, M., Mohri, H., 2007. Spermatogenesis in the testes of diapause and non-diapause pupae of the sweet potato hornworm, Agrius convolvuli (L.)(Lepidoptera: Sphingidae). Zool. Sci. 24, 1036-1044.

Sonnenschein, M., Hauser, C.L., 1990. Presence of only eupyrene spermatozoa in adult males of the genus, Micropterix Hubner and its phylogenetic significance (Lepidoptera: Zeugloptera, Micropterigidae). Int. J. Insect Morphol. Embryol. 19, 269-276.

Spurgeon, D.W., Raulston, J.R., 1998. Diapause induction in subtropical boll weevils. Cotton Insect Research and Control Conference, 1019-1025.

Tibout, E., 1980. Evolution and Role of Apyrene Sperm Cells of Lepidopterans: Their Activation and Denaturation in the Leek Moth, Acrolepiopsis Assectella (Hypomeutoidea). In: In: Clark Jr.W.H., Adams, T.S. (Eds.), Advances in Invertebrate Reproduction Elsevier North Holland Inc, pp. 231-242.

Tschudi-Rein, K., Benz, G., 1990. The bipotentiality of lepidopteran primary spermatocytes questioned. Mitteilungen der Schweizerischen Entomologischen Gesellschaft Bulletin de la Société Entomologique Suisse 63, 81-85.

Yamagishi, M., Ito, Y., Tsubaki, Y., 1992. Sperm competition in the melon fly, Bactrocera cucurbitae (Diptera: Tephritidae): effects of sperm "longevity" on sperm precedence. J. Insect Behav. 5, 599-608. 